\title{
Bifosfonatlar ve çene kemiğinde görülen osteonekroz
}

\author{
Elif Tarım Ertaş ${ }^{1}$, Meral Yırcalı Atıcı ${ }^{1}$
}

Selcuk Dental Journal, 2015; 2: 91-100

Başvuru Tarihi: 31 Ekim 2014 Yayına Kabul Tarihi: 11 Mayıs 2015

\section{Bisphosphonates and osteonecrosis of the jaws}

Bisphosphonates, which are synthetic analogues of pyrophosphates are widely used in treatment of in many diseases of bone metabolism. Administration of biphosphanates may cause adverse effects such as osteonecrosis of the jaws. Preventive procedures and early diagnosis are important due to the difficult osteonecrosis management and adverse effects of the patient life. For this reason, it is important to identify the clinical and radiographic features of the bisphosohonaterelated osteonecrosis of the jaws in order to provide early diagnosis and treatment.

The aim of this review is to give the knowledge about bisphosphonates and to draw attention to the important point of diagnosis of bisphosphonate-related osteonecrosis of the jaws. In addition, prevention and protection of osteonecrosis, which are very important for patients, will be discussed.

\section{KEY WORDS}

Bisphosphonates, jaw, osteonecrosis, risk factors

Kemik rezorpsiyonunu engellediğ bilinen endojen pirofosfatazların analogları olan bifosfonatlar, tıp alanında ilk olarak 1868 yılında böbrek taşı oluşumunu önlemek için kullanılmıştır (Reid 2008). Günümüzde özellikle osteoporoz tedavisinde yaygın olarak kullanılmaya başlanan bifosfonatlar, kemik metastazlarıly seyreden meme, prostat, akciğer kanserleri, multiple myeloma gibi malignitelerin, osteopeni, Paget hastalığı, osteogenezis imperfekta gibi sistemik hastalıkların tedavisinde kullanılmaktadır (Harris ve ark 1999, KamounGoldrat ve ark 2008, Walter ve ark 2008, Woo ve ark 2006).
Bifosfonatlar, doğrudan kemik yıkımından sorumlu olan osteoklastik aktiviteyi inhibe ederek etkisini gösterirler (Gomez Font ve ark 2008). Aynı zamanda bu ilaçlar, osteoblastik aktiviteyi de engellerler (Naidu ve ark 2008). Tedavide önemli yarar sağlamalarına rağmen, çok sayıda çalışmaya konu olmuş göz ardı edilemeyecek yan etkilere de sebep olabilirler. Önemli yan etkileri arasında, böbreklerde toksisite, gastrointestinal rahatsılılıklar, hepatoksisite, hipokalsemi, atriyal fibrilasyon, elektrolit dengelerinde bozulma, kas ve kemik ağrıları sayılabilir (Pazianas ve ark 2010, Suresh ve ark 2014). Çene bölgesinde ise, çeşitli faktörlere bağlı olarak, hastaların yaşam kalitelerini olumsuz etkileyen osteonekroza sebep olabilirler (Marx 2003, Migliorati ve ark 2010).

Bu derlemenin amacı, bifosfonatlar hakkında güncel bilgi vermek, bifosfonata bağlı çenelerde görülen osteonekroz tanısında önemli olan noktalara dikkat çekmektir. Aynı zamanda radyografik tanı hakkında bilgi verilerek, hastalar için çok önemli olan osteonekrozdan korunma ve önleyici tedbirlere değinilecektir.

\section{Bifosfonatların kimyasal yapısı}

Pirofosfatlar, merkezi oksijene baghı iki fosfonat grubu içerir, bifosfonatlarda merkezde oksijen yerine karbon vardır ve karbon atomuna bağlı 2 yan zincire sahiptir. Pirofosfatlar ve bifosfonatların aralarındaki kimyasal farklılık, bifosfonatların asidik ortamda hidrolize olmasını engelleyerek dokularda daha uzun süre kalmasını saglar (Gomez Font ve ark 2008, Verron veBouler 2014). Merkezi karbon atomu ve karbon atomuna bağlı 2 yan zincire (R1R2) sahip bifosfonatlar, hidroksiapatit kalsiyum şelasyonu yapabilirler ve öncelikle yenilenen kemik yüzeyleri olmak üzere, kemiklere güçlü afiniteleri vardır (Şekil-1).

\footnotetext{
${ }^{1}$ İzmir Katip Çelebi Üniversitesi Diş Hekimliği Fakültesi Ağız Diş ve Çene Radyolojisi Anabilim Dalı, İzmir, Türkiye
} 

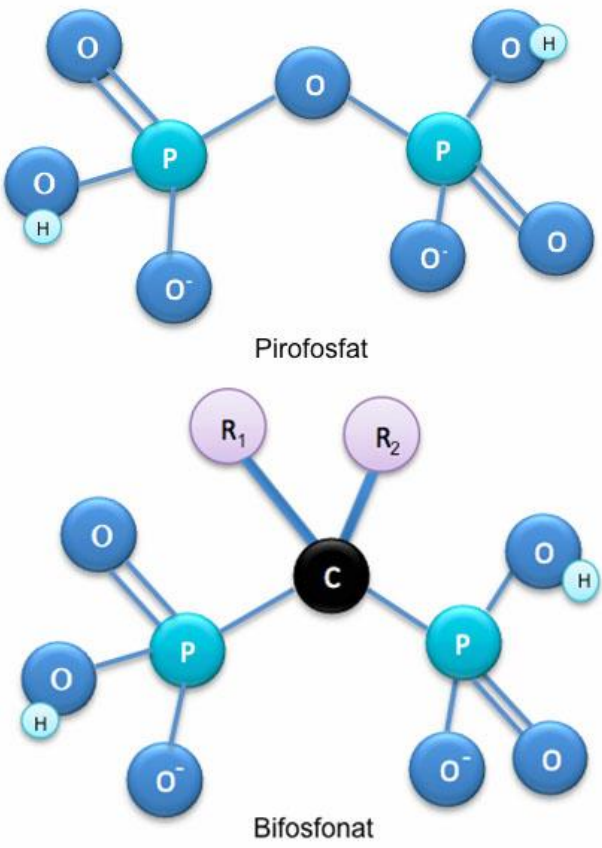

Şekil 1.

Bifosfonat ve pirofosfatların kimyasal yapısı

R1 zinciri kemiğe bağlanma afinitesini sağlar. Kemik rezorpsiyonunu önleyici etkiden sorumlu asıl zincir nitrojen grubu olan R2 zinciridir (Rizzoli 2011).

Bifosfonatlar nitrojen içeriklerine göre, nitrojen içermeyen (alkalibifosfonatlar) ve nitrojen içeren (aminobifosfonatlar) olmak üzere bașlıca iki gruptan oluşmaktadır (Crepin ve ark 2010). Illacın molekül yapısında değșiklikler yapılarak üç kuşak bifosfonat üretimi yapılmıştır.

'Birinci kuşak bifosfonatlar' nitrojen içermez ve R2 zincirleri kısadır ve vücutta çok hızlı metabolize edilirler. Birinci kuşak bifosfanatlar, gücü en az olan gruptur (Crepin ve ark 2010, Ebetino ve ark 2011, Vassiliou ve ark 2010).

Birinci kuşak (Nitrojen içermeyen) bifosfonatlar ve ticari isimleri:

1. Etidronat (Difosfen $\AA$, Osteum $\left.{ }^{\circledR}\right)$

2. Tiludronat (Skelide $\left.{ }^{\circledR}\right)$

3. Klodronat (Bonefos $\left.{ }^{\circledR}\right)$

Nitrojen içeren 'ikinci ve üçüncü kuşak bifosfonatlar' uzun R2 zincirlerine sahiptir. Merkezi karbon atomuna bagłı nitrojen grubu sayesinde nitrojen içermeyen bifosfonatlardan daha güçlüdürler.

Yan zincirlerinde nitrojen içeren ikinci kuşak bifosfonatlar, birinci kușak bifosfonatlardan 10-1000 kat daha güçlüdürler (Crepin ve ark 2010, Ebetino ve ark 2011).
Ikinci kuşak bifosfonatlar ve ticari isimleri:

1. Alendronat (Fosamax $\left.{ }^{\circledR}\right)$

2. Pamidronat (Aredia ${ }^{\circledR}$ )

Üçüncü kuşak bifosfonatlar bir heterosiklik halka içinde bir nitrojen atomu intiva eder ve birinci kușak bifosfonatlardan 100-10000 kat daha güçlüdürler (Crepin ve ark 2010, Ebetino ve ark 2011).

Üçüncü kuşak bifosfonatlar ve ticari isimleri:

1. Risedronat (Actonel $\AA$, Acrel $\AA$ )

2. Ibandronat (Boniva $\left.{ }^{\circledR}\right)$

3. 3-Zoledronat (Zometa $\left.{ }^{\circledR}\right)$

\section{Bifosfanatların endikasyonları}

\section{Osteoporoz}

Bifosfonatlar günümüzde yaygın olarak menapoz sonrası dönemde kadınlarda profilaktik veya terapötik amaçlı olarak kemik mineral densitesini artırdığ ve osteoporoza bağı oluşan kemik kırıklarını azalttıgı için kullanılmaktadır (Cummings ve ark 1998, Harris ve ark 1999).

Bifosfonatlar ayrıca yașlanmaya, glukokortikoid kullanımına ve östrojendeki azalmaya bagłı osteoporoz tedavisinde de kullanılmaktadır (Adachi ve ark 2001, Pazianas ve ark 2007).

\section{Metabolik kemik hastalıkları}

Paget hastalığ, fibröz displazi, heterotropik ossifikasyonlar, ankilozan spondilit gibi metabolik kemik hastalıklarının tedavisinde de tercih edilen bir ilaç grubudur (Kamoun-Goldrat ve ark 2008, Katz 2005, Marx ve ark 2007, Woo ve ark 2006).

\section{Kemik metastaz riski olan kanserler}

Bifosfonatlar tümör hücrelerini inhibe ederler, bu nedenle kemik metastaz riski olan göğüs, prostat ve akciğer gibi kanserlerin tedavisinde kullanılmaktadır (Aoyagi ve ark 2013, Walter ve ark 2009, Walter ve ark 2008).

\section{Multiple myeloma}

Multiple myleomada iskeletsel deformitelerini engellemek için kullanılmaktadır.

\section{Osteogenezis imperfekta}

Osteogenezis imperfektada kemik kırılganlığnı önlemeye yönelik olarak da kullanılmaktadır (Kamoun-Goldrat ve ark 2008, Leite ve ark 2006).

\section{Gaucher Sendromu}

Bununla birlikte, klinik bulgularından biri osteoporotik kemik lezyonları olan Gaucher endromu'nun tedavisinde de bifosfonatlar kullanılmaktadır (Landesberg ve ark 2009). 


\section{Bifosfonata bağlı çene kemiği osteonekrozu}

Illk kez Marx tarafından 2003 yılında rapor edilen, bifosfanat kullanımının çene kemikleri üzerinde şiddetli bir komplikasyonu olan bifosfonata bağlı çene kemiği osteonekrozu (BON), baş ve boyun bölgesinden radyoterapi görmemiş, bifosfonat ile tedavi edilmiş veya edilmekte olan hastalarda, 8 haftadır iyileşmeyen, maksillofasiyal bölgede açıkta kemik lezyonları olarak tanımlanabilir (Marx 2003, Ruggiero ve ark 2009) (Resim1).

Tam olarak insidansı bilinmemekle birlikte, yapılan çalışmalar, vaka raporları değerlendirildiğinde kümülatif ortalamanın \%0.8 ile \%12 arasında olduğu bildirilmiştir (Ruggiero ve ark 2009).

Mandibulanın kanlanmasının maksillaya göre az olması ve kompakt yapısı nedeniyle en fazla mandibulada (\%60) daha sonra maksillada (\%30) görülmektedir. Her iki çenede görülme oranı \%10'dur (Lehrer ve ark 2009).

İlacın çeşidi, kullanım yolu ve süresi oluşumunda en etkili faktörlerdir.

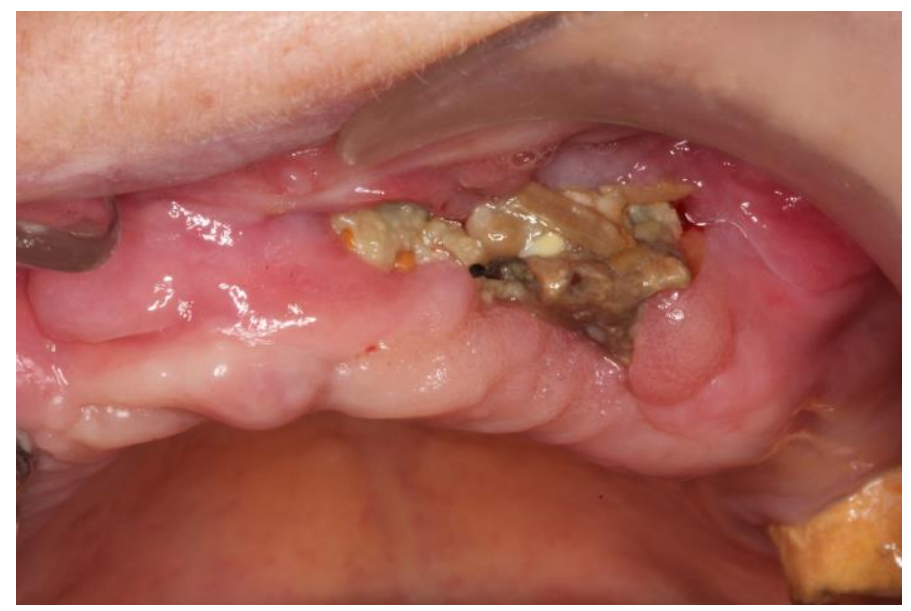

Resim 1.

4 yıl süre ile oral bifosfanat (residronat) kullanan 77 yaşındaki hastanın ağız içi fotoğrafı

Literatürde rapor edilmiş 626 vakada \%92.7, zoledronik asit (\%42.6), pamidronat (\%26.9) veya her ikisinin birden (\%23.2) kullanıldığı gösterilmiştir. Nitrojen içeren bifosfanatların intravenöz olarak 3 yıldan fazla kullanılması riski arttırır (Migliorati ve ark 2010). Kemoterapötik ajanlar ve kortikosteroid kullanan çoğu hastanın bifosfonat da kullanıyor olması, iyileşmenin bozulmasına ve osteonekroz oluşma olasılığını arttırır. Östrojen tedavisi, alkolizm, kanser, yaşlılık, anemi, diabet ve sigara kullanımı gibi iyileşme kapasitesini etkileyen sistemik faktörler osteonekroz gelișim riskini arttırır. Ayrıca kötü ağız hijyeni, uyumsuz protezler, cerrahi işlemler, periodontal hastalıklar gibi dental faktörler de BON gelişiminde etkili olabilirler. Torus ve eksostozlar, belirgin mylohyoidea gibi anatomik farklılıklarda etkenler arasında sayılmaktadırlar (Abu-ld ve ark 2008) (Tablo-1).
Diş çekimi, dental implant gibi cerrahi işlemlerin veya periapikal apse gibi lokal patolojilerin gelișme insidansının spontan gelişmeye oranla arttırdığ bildirilmiștir. Marx ve ark. (2005) yaptıkları çalışmada 119 BON vakasının \%25,2 spontan olarak, \%37,8 dis, çekimi sonrası, \%28,6 periodontal hastalıga bagłı, $\% 11,2$ periodontal cerrahi sonrası ve \%0,8 apikal rezeksiyon sonrası oluştuğunu bildirmişlerdir.

\section{Tablo 1.}

\section{BON risk faktörleri (Regezi ve ark 2012)}

\begin{tabular}{|l|}
\hline BON RISK FAKTÖRLERI \\
\hline ILAÇ iLişKiLi \\
Yüksek doz ilaç kullanımı \\
Uzun süre ilaç kullanımı \\
Yüksek ilaç potansiyeli \\
İntravenöz bifosfonat kullanımı \\
DENTAL VEYA LOKAL FAKTÖRLER \\
Kötü ağız hijyeni \\
Uyumsuz protezler \\
Periodontal hastalıklar \\
Dentoalveolar enfeksiyon \\
Anatomik faktörler \\
SisTEMiK FAKTÖRLER \\
Hastanın kullandığı ilaçlar \\
Kemoterapötik ilaçlar \\
Sistemik kortikosteroidler \\
Kanser \\
Diabet \\
Sigara kullanımı \\
\hline
\end{tabular}

BON klinik olarak ağrı, ağı içinde yumuşak dokuda șişlik, dișlerde lüksasyon, direnaj, açıga çıkmıs, gri-sarı renkte kemik yüzeyi ile karakterizedir (Ruggiero ve ark 2009) (Resim-2a, b). Fakat hastalarda sebebi anlaşılamayan spesifik olmayan bulgular da görülebilir. BON tanısında spesifik olmayan bulgular dișlerde hassasiyet, mukozada ülserasyon, yumusak dokuda șişlik, spontan olabileceğ gibi özellikle çiğnerken veya dis, fırçalarken görülen șiddetli ağı̆, maksiller sinüs bölgesi tutulumunda sinüzit, oroantral fistül, mukoperiosteal genisleme, iltihabik direnaj, akut apse, alveol kemikte ekspoz, osteomyelit, trismus, halitosis, deride fistülizasyon, parestezi/anestezi, aktinomiçes infeksiyonu şeklinde sıralanabilir (Bianchi ve ark 2007, Naveau ve Naveau 2006).

BON dental ya da periodontal bir rahatsızlıgin bulgularılya kendini belli edebilir. Bu nedenle bifosfonat kullanan hastalarda dental tedavi sonrası semptomlarda düzelme olmuyorsa osteonekroz düşünülmelidir. Klinik muayene ve bulgulara ek olarak, tanıyı doğrulama ve hastalığın hangi aşamada olduğunun belirlenmesi için radyografik tanıya intiyaç vardır. 

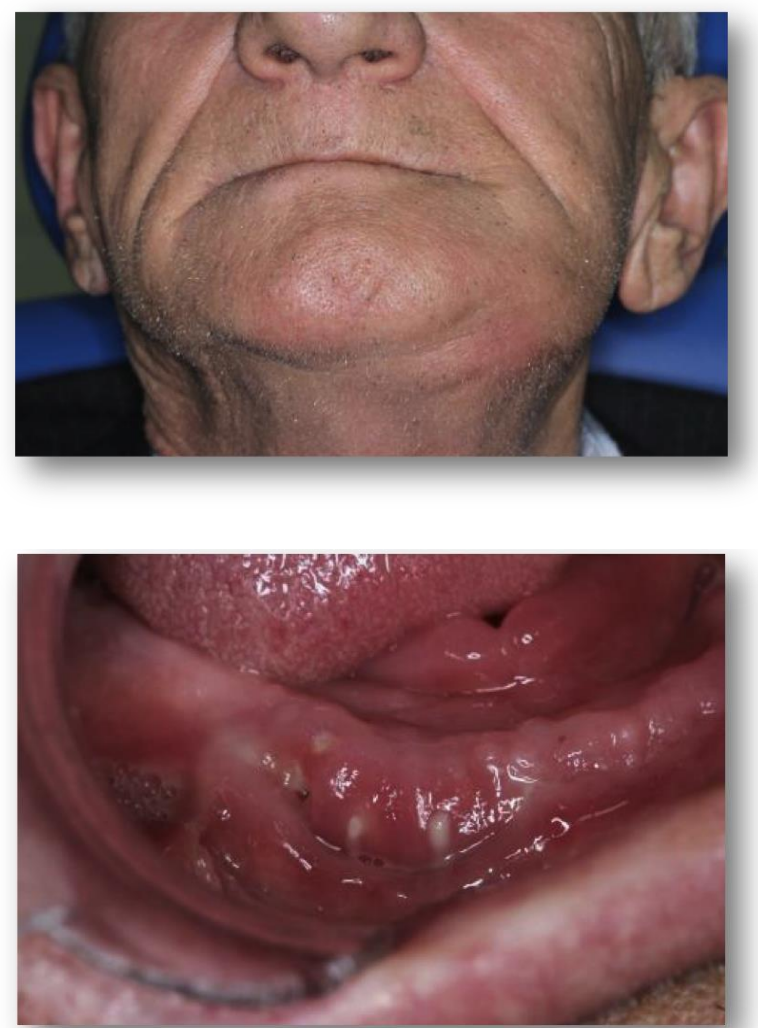

Resim 2.

a) 67 yaşındaki akciğer ca olan, intravenöz zoledronik asit kullanan hastadaki ekstraoral şişlik

b) Aynı hastadaki intra oral fistüller

\section{Bifosfonata bağlı çene kemiği osteonekrozu}

BON tanısının konulabilmesi için klinik muayene ile radyografik muayane birlikte yapılmalıdır. Ekspoze kemik klinik olarak görülmediği halde, radyografik değerlendirme ile erken tanı konabilir. Amerikan Oral ve Maksillofasiyal Cerrahi Dernegi (AAOMS) 2009 yılında BON sınıflamasına nekrotik kemik oluşmadan, spesifik olmayan semptomları olan evre 0 hastalarını dahil etti (Tablo-2). Bu semptomlar;

1. Dental sebebi bulunmayan ağrı veya künt kemik ağrısı,

2. Kronik periodontal hastalık olmadan dişte mobilite ve/veya çürük sebepli pulpal nekrozla ilişkili olmayan periodontal/periapikal fistül veya

3. Kronik periodontal hastalık ile ilişkili olmayan alveolar kemik kaybı, trabeküler kemik değişiklikleridir. (kemik yoğunluğu değişimi, çekim bölgesinde remodele olmayan kemik, lamina dura kalınlaşması ve inferior alveolar kanal daralması) (Ruggiero ve ark 2009).
Tablo 2.

Amerikan Oral ve Maksillofasiyal Cerrahi Dernegi (AAOMS) BON vakalarını risk kategorilerine göre sıniflandırmıştır (Ruggiero ve ark 2009)

\begin{tabular}{|l|l|}
\hline $\begin{array}{l}\text { Risk } \\
\text { grubu } \\
\text { hastaları }\end{array}$ & $\begin{array}{l}\text { Klinik olarak nekrotik kemik yok, semptom yok, oral } \\
\text { veya intravenöz bifosfanat kullanan hastalar }\end{array}$ \\
\hline 0. EVRE & $\begin{array}{l}\text { Klinik olarak nekrotik kemik yok, nonspesifik klinik } \\
\text { bulgular ve semptomlar var. }\end{array}$ \\
\hline 1. EVRE & $\begin{array}{l}\text { Klinik olarak enfeksiyon bulgusu olmadan, } \\
\text { asemptomatik hastalarda ekspoze ve nekrotik kemik } \\
\text { var. }\end{array}$ \\
\hline 2. EVRE & $\begin{array}{l}\text { Pürülan drenaj olmadan, ekspoze kemik bölgesinde } \\
\text { eritem ve ağı̆ bulguları ile seyreden enfekte ekspoze } \\
\text { nekrotik kemik var. }\end{array}$ \\
\hline 3. EVRE & $\begin{array}{l}\text { Ağı̆ olan hastalarda nekrotik ve açığa çıkmıs, kemik, } \\
\text { Aşağdaki klinik bulgulardan birinin veya daha fazlasının } \\
\text { varlığ; } \\
\text { Alveolar kemik alanının dıșnda ekspoze ve nekrotik } \\
\text { kemiğin genișlemesi (mandibulanın alt sınırı, ramus, } \\
\text { maksillar sinüs ve maksillanın zigomatik çıkıntısı) } \\
\text { sonucu patolojik fraktür olușması; } \\
\text { Ekstraoral fistül; oroantral ve/veya oronazal } \\
\text { baglantı;veya mandibulanın alt sınırı veya sinüs } \\
\text { tabanında osteolizisin genișlemesi }\end{array}$ \\
\hline
\end{tabular}

Radyografik bulgular spesifik olmasa da radyografik muayene erken tanı için önemlidir. Bu hastalarda sklerotik alanlar, organize olmayan medullar trabekülasyon, alveolar kenarlar ve lamina durada yoğun osteoskleroz, çekim sonrası alveolar soketin kalması ve küçük kemik sökestrleri görülebilir. Lezyon ilerledikce ise genis, radyolusent alanlar, bazen çene kemiğ fraktürleri görülebilir (Chiandussi ve ark 2006, Phal ve ark 2007) (Resim-3).

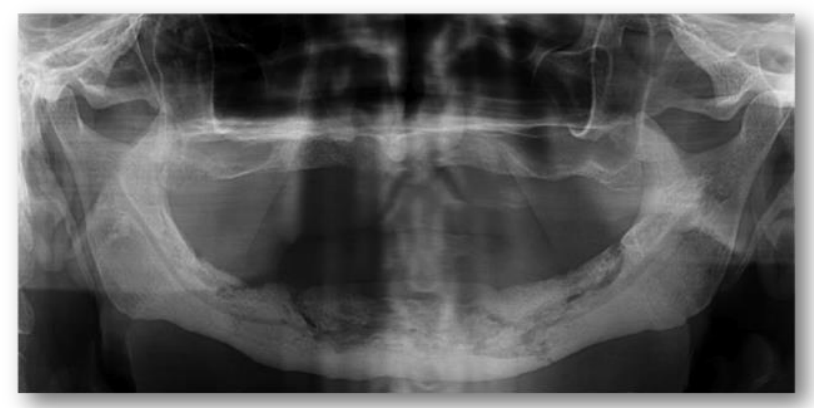

Resim 3.

a) Geniş radyolüsent alanlar ve çene kemiğinde patolojik fraktür

BON'un radyolojik değerlendirmesinde konvansiyonel radyografi, bilgisayarlı tomografi (BT), dental volumetrik tomografi (DVT), manyetik rezonans görüntüleme ve kemik sintigrafisi kullanılır (Arce ve ark 2009). 
Periapikal ve panoromik radyografiyi içeren konvansiyonel radyografi, çabuk görüntü almamıza olanak sağlar fakat kemik değişikliklerinin radyografik bulgu vermesi 2 hafta kadar sürebilir (Chiandussi ve ark 2006, Ruggiero ve ark 2004). 2 boyutlu radyografilerdeki bulgular, lamina dura kalınlaşması, osteoliz, diffüz skleroz ve çekim bölgelerinin eksik veya hiç iyileşmemesini içerir. Skleroz seviyesi arttıkça hastalığın şiddeti de artar. İleri vakalarda, parestezi sebebi olabilen mandibular kanalın daralması görülebilir (Phal ve ark 2007).

Sonis ve ark. (2009)'nın yaptıkları hayvan deney çalışmasında, subkutan olarak deney grubundaki yetişkin dişi farelere deksametazon ve zoledronik asit enjekte edilmiştir. Daha sonra molar dişlerinin çekimini takiben, klinik, radyolojik ve histolojik değerlendirme yapılmıştır. Çekim bölgesinden alınan 2 boyutlu radyografilerde, kontrol grubunda gözlenmeyen radyoopak-radyolusent alacalı trabeküler yapı gözlemlenmiştir.

BON hastalarının radyografik tanısında BT kullanılabilir. BT görüntüleri, konvansiyonel filmlerle bulguların belirlenmesinin zor olduğu durumlarda yardımcıdır. Ayrıca üç boyutlu görüntü elde edilir ve lezyonun sınırlarının belirlenmesini daha net bir şekilde sağlar. Görüntüleme teknikleri ile belirlenen lezyon, klinik olarak ekpoze kemikten daha geniştir (Bedogni ve ark 2008). Panoramik görüntüler ile BT karşılaştırıldığında, panoromik filmler rezolüsyonunun düşük olması nedeniyle bazı nekrotik alanların gözden kaçmasına neden olabilir (Bianchi ve ark 2007).

Radyografik BT bulguları, erken evrede organize olmayan, trabeküler ve zayıf kortikomedüller değişim ile birlikte fokal sklerozisdir (Bisdas ve ark 2008). Hastalık ilerledikçe, periostal reaksiyon ve sökestrasyon görülür (Bianchi ve ark 2007). Periostal yeni kemik oluşumu da radyografik bir bulgudur. Ayrıca ekspoze kemikteki enfeksiyona bağlı servikal adenopati bir BT bulgusudur. Çiğneme kaslarında belirgin, tümöre benzer kalınlaşma görülebilir. Maksiller BON vakalarında maksiller sinüse komşu alanlarda mukoperiostal kalınlaşma ve fistül oluşumu görülebilir (Bedogni ve ark 2008, Bianchi ve ark 2007, Raje ve ark 2008). Maksiller sinüste ayrıca yeni kemik oluşumu görülebilir (Arce ve ark 2009).

Bianchi ve ark. (2007) 32 BON hastasının BT ve panoramik görüntülerini değerlendirdikleri çalışmaları sonucunda sökestr formasyonu ve üç boyutlu değişikliklerin boyutlarının tespitinde BT'nin panoramik radyografiye üstünlüğünü göstermişlerdir. Fullmer ve ark. (2007) ise iki vakada sklerozis ve yüzey düzensizliklerini DVT ile göstermişlerdir. DVT düşük doz radyasyon, yüksek çözünürlük ve kısa tarama zamanı ile BT ile karşılaştıııldığında BON tanısında BT'nin sagladığ radyografik bilgiyi daha kısa sürede ve daha düșük doz ile sağlamaktadır (Barragan-Adjemian ve ark 2009, Scarfe ve ark 2006, Singer veMupparapu 2009).

Konvansiyonel radyografi, BON riski olan hastaların takibinde ve hastalığın seyrinde kullanılabilir. BT ve DVT gibi 3 boyutlu ileri görüntüleme teknikleri ise lezyon sınırlarının, boyutlarının ve komşu yapılarla ilişkilerinin önemli olduğu cerrahi öncesi önem kazanır (Bianchi ve ark 2007, Soğur ve ark 2012). Manyetik rezonans görüntülemenin BON değerlendirilmesinde kullanılması kemik tutulumunu, etraf yumuşak doku, nörovasküler lif ve lenfadenopatinin değerlendirilmesine olanak verir. Ödem veya enflamasyon ile ilişkili su miktarındaki artış sonucu kemik iliği değişikliklerini MRG gösterebilir. Bu değişiklikleri düşük sinyal intensitesinde T1 ağırlıklı görüntüler ve yüksek sinyal intensitesindeki T2 ağırlıklı görüntüler gösterir. Nekroz oluştuğunda, düşük sinyal alanları her iki T1 ve T2 ağırlıklı görüntülerde artmış sinyal intensite halkası ile çevrilidir (Unger ve ark 1988). Kemik iliğindeki bu değişiklikler kırıkların iyileşmesi ve metastazlarda, kemiğin non- enflamatuar durumlarında görülebilir (Arce ve ark 2009).

Mandibulanın osteomyelitinde geleneksel radyografilerle kemik değişiklikleri gözlenmeden akut faz değişikliklerini MRG gösterebilir (Ariji ve ark 2008). Benzer bulgular BON hastalarında da gösterilmiştir. Garcia-Ferrer ve ark. (2008) 14 hastayı dahil ettikleri çalışmalarında, klinik fokal lezyonlar gözlenmeden, MRG ile osteonekroz belirlemişlerdir.

BON hastalarında MRG ile kanselöz kemik değişiklikleri belirlenebilir. Çenelerin canlı bölgelerinde T1 ağırlıklı görüntülerde düşük sinyal intensitesi ve T2 ağırlıklı görüntülerde yüksek sinyal intensitesi görülür (Bisdas ve ark 2008, Chiandussi ve ark 2006, Raje ve ark 2008). Nekrotik alanlarda ise hem T1 hem T2 ağırlıklı görüntülerde hipointens alanlar vardır. Bedogni ve ark. (2008) BON hastasının MRG ve histopatolojik bulgularını rapor etmişlerdir. MRG sonuçlarında, iki kemik hastalığı paterni göstermişlerdir. Ekspoze kemiğin olduğu bölgelerde iyileşme alanlarının tersine T1 ve T2 ağırlıklı görüntülerde düşük sinyal görülmüş (düşük su içeriği). Diğer patern olarak ise ekspoze olmamış kemik alanlarında T1 ağırlıklı görüntülerde düşük sinyal intensitesi ve T2 ağırlıklı görüntülerde yüksek sinyal intensitesi görüldüğünü açıklamışlardır.

Nükleer kemik görüntüleme (sintigrafi); BON'un erken tanısında diğer bir alternatif görüntüleme yöntemidir. Sintigrafi kemik yogunlugundaki değșiklikleri göstererek nekroz bașlangıcı, nekroza yatkın kemik metabolizmasında bozulmaların oldugu bölgeleri veya nekrozun subklinik evrelerini göstererek 
bifosfonatı düzenli kullanan hastalarda osteonekrozlar oluşmadan önce \%66 gibi bir oranla erken tanıya yardımcı olabilmektedir (O'Ryan ve ark 2009). Teknesyum-99m-metilen difosfat ile yapılan kemik sintigrafisi çalışmaları ile erken dönem tanıda diğer görüntüleme yöntemlerine göre sintigrafinin üstünlüğü gösterilmiştir (Dore ve ark 2009). Fakat düşük çözünürlüklü sintigrafi görüntülerinde lezyon boyutları saptanamaz ve enflamatuar ve malign değişim ayrımı yapılamaz (Stockmann ve ark 2010).

\section{BON Önleyici tedbirler}

Hasta bifosfonat tedavisine başlayacaksa gerekli tedaviler yapılıp koruyucu önlemler alınmalıdır. Özellikle invaziv ișlemler bașta olmak üzere tüm dental tedaviler bifosfonata başlanmadan bitirilmelidir. Radikal tedaviler uygulanarak daha sonra oluşabilecek riskler en aza indirilmelidir. Hasta osteonekroz riski konusunda bilgilendirilmelidir. Düzenli kontrollerin gerekliliği ve ağz hijyeninin önemi belirtilmelidir. Invaziv dental ișlemler özellikle intravenöz veya yüksek doz bifosfonat kullanan hastalarda mümkün oldugunca önlenmelidir. Bu hastaların protez uyumuna dikkat edilmelidir, oluşan herhangi bir problemde doktorlarını bilgilendirmeleri konusunda uyarılmalıdırlar (Leite ve ark 2006). Kortikosteroid ile birlikte bifosfanat kullanan hastalar gibi yüksek risk grubundaki hastalar, sigara ve alkol kullanmamaları konusunda bilgilendirilmelidir (Khan ve ark 2008).

Uluslararası Myeloma Kuruluşu (International Myeloma Foundation) bifosfonat kullanan hastalarda oral cerrahi ișlem gerekmesi durumunda 2-4 ay ilacın kesilmesinin osteonekroz riskini belirgin ölçüde azalttıgı̆nı belirtmektedir. Bifosfonatlar kemikte uzun süre kalabilmelerine rağmen ilaca bu şekilde ara verilmesi anjiogenik etkiyi bozar (Gutta veLouis 2007). Marx ve ark (2007) ise nekroz riskinin tamamen ortadan kalkması için tedaviye 6-9 ay ara verilmesi gerektiğini önermişlerdir.

\section{BON Tedavisi}

BON hastalarında tedavi yaklaşımı hastaların eğitilmesi, ağrı kontrolü, yumuşak ve sert dokudaki sekonder enfeksiyonun kontrolü ve lezyonun genişlemesi ve yeni nekroz alanlarının oluşmasının önlenmesini kapsar. Amerikan Oral ve Maksillofasiyal Cerrahi Dernegi (AAOMS) 2009 yılında BON olgularına yönelik olarak yayımladıgı bildiride; BON vakalarını risk kategorilerine göre sınıflandırmıs, ve bu sınıflamalara uygun tedavi yaklașımları belirlemiştir (Tablo-2).

\section{Evrelere göre tedavi planlamasi:}

Risk grubundaki hastalar: Oral veya intravenöz bifosfanat kullanan bu hastalar, bifosfonatların osteonekroz riski hakkında bilgilendirilmeli, hastalığın semptomları hakkında bilgi verilmeli ve iyi bir ağız hijyeninin önemi vurgulanmalı ve kontrolleri yapılmalıdır.

Evre 0: Semptomatik tedavi gereklidir. Çürükler ve periodontal tedaviler gibi diğer lokal faktörler konservatif olarak tedavi edilmelidir. Sistemik tedavi gerektiğinde kronik ağrı ve enfeksiyon kontrolünda ağrı kesici ve antibiyotik kullanımını içerir.

Evre 1: Cerrahi tedavi gerektirmez. Hastalar \%0.12'lik klorheksidin gibi antimikrobiyal gargaralardan faydalanabilirler.

Evre 2: Bu hastalarda antimikrobiyal ağız gargaraları ile birlikte antibiyotik kullanımı gereklidir. Penisilin grubu antibiyotikler çoğu izole edilen mikroorganizmaya etkilidir. Metronidozol, doksisiklin, klindamisin ve eritromisin penisilin alerjisi olan hastalarda kullanılabilir. Ayrıca mikrobiyal kültürler aktinomiçes türü bakterilerin analizi için yapılmalıdır. Eğer aktinomiçes tespit edilirse antibiyotik tedavisi bu bakteriye uygun yapılmalıdır. İnatçı vakalar, kombine antibiyotik kullanımı, uzun süreli antibiyotik kullanımı ve intravenöz antibiyotik kullanımı gerektirebilir.

Evre 3: Rezeksiyonu içeren debridman bu hastalar için faydalıdır. Kombine antibiyotik tedavisi uzun süreli ağrı ve akut enfeksiyonda hafifleme sağlayabilir (Ruggiero ve ark 2009).

Hastalığın evresinden bağımsız olarak, hareketli olan sökestr, yeni kemik açığa çıkartılmadan uzaklaştırımalıdır. Ekspoze, nekrotik kemik içindeki semptomatik dişin çekimi lezyonda herhangi bir alevlenmeye sebep olmayacağı için yapılabilir (Ruggiero ve ark 2009). Tedaviye cevap vermeyen inatçı vakalarda trombositden zengin plazma veya parathormon uygulaması ile birlikte marjinal kemik rezeksiyonu yapılabilir (Lee ve ark 2007, Vassiliou ve ark 2010). Ayrıca hiperbarik oksijen tedavisinin yara iyileşmesi ve ağrıda azalma sağladığı bildirilmektedir (Freiberger 2009). Stübinger ve ark. yaptıkları çalışma ile Er:YAG lazerin operasyon sonrası iyileşmede komplikasyonu önlediğini göstemişlerdir (2009). Ayrıca bu tedavilere ek olarak ozon terapisinden de faydalanılabilinir. Agrillo ve ark. (2007) non-invaziv cerrahi öncesi ve sonrası antibiyotik ve antifungal tedavi ile birlikte ozon terapisi uygulamışlar ve iyileşmenin komplikasyonsuz gerçekleştiğini ve semptomların kaybolduğunu bildirmişlerdir. 


\section{SONUÇ}

Bifosfonata bağlı çene kemiği osteonekrozu, hastaların yașam kalitelerini olumsuz yönde etkileyen kesin bir tedavisi olmayan çene kemiğinin önemli lezyonlarıdır. Hastaların konforu ve hastalığın ilerlemeden tedavisi için erken tanı önemlidir. Yapılan detaylı anamnez, iyi bir klinik ve radyografik muayene tanıyı kolaylaştıır ve hastanın tedaviye daha kısa sürede ulaşmasını sağlar. Bu nedenle diş hekimlerinin BON hakkında bilgiye sahip olması, hastalarını bilgilendirmesi önemlidir. Gerekli tüm önlemler osteonekroz oluşmadan önce alınmalıdır. Hastalar ağız hijyenine önem vermeli, travma oluşmasını engellemelilerdir. Aynı zamanda bifosfanatları reçete eden hekimlerinde ilacın çene kemiği üzerindeki etkileri hakkında bilgi sahibi olması ve hastalarını bilgilendirerek, imkan varsa tedavi başlangıcı öncesi diş hekimlerine yönlendirmeleri gerekmektedir.

\section{Bifosfonatlar ve çene kemiğinde görülen osteonekroz}

Pirofosfatların sentetik analogları olan bifosfonatlar kemik metabolizması ile ilgili birçok hastalığın tadavisinde yaygın olarak kullanılmaktadırlar. Bifosfonatların kullanımının hastaya sağladığı yarar yanında, çenelerde osteonekroz oluşması gibi yan etkileri de vardır. Bifosfonata bağı gelişen osteonekrozun tedavisinin zorluğu ve hastanın hayatını olumsuz etkilemesi erken tanı ve koruyucu önlemleri önemli yapar. Bu nedenle bisfosfonat osteonekrozuna ait klinik ve radyografik özelliklerin iyi bilinmesi erken tanı ve tedavi açısından önem taşımaktadır.

Bu derlemenin amacı bifosfonatlar ile ilgili bilgi vermek, bifosfonata bağlı çenelerde görülen osteonekroz tanısında önemli olan noktalara dikkat çekmektir. Ayrıca, hastalar için çok önemli olan osteonekrozdan korunma ve önleyici tedbirlere de değinilecektir.

\section{ANAHTAR KELIMELER}

Bifosfonat, çene, osteonekroz, risk faktörleri

\section{KAYNAKLAR}

Abu-ld MH, Warnke PH, Gottschalk J, Springer I, Wiltfang J, Acil Y, Russo PA, Kreusch T, 2008. "Bisphossy jaws" - high and low risk factors for bisphosphonate-induced osteonecrosis of the jaw. J Craniomaxillofac Surg, 36, 95-103.

Adachi JD, Saag KG, Delmas PD, Liberman UA, Emkey RD, Seeman E, Lane NE, Kaufman JM, Poubelle PE, Hawkins F, Correa-Rotter R, Menkes CJ, RodriguezPortales JA, Schnitzer TJ, Block JA, Wing J, Mcllwain $\mathrm{HH}$, Westhovens R, Brown J, Melo-Gomes JA, Gruber BL, Yanover MJ, Leite MO, Siminoski KG, Nevitt MC, Sharp JT, Malice MP, Dumortier T, Czachur M, Carofano W, Daifotis A, 2001. Two-year effects of alendronate on bone mineral density and vertebral fracture in patients receiving glucocorticoids: A randomized, double-blind, placebo-controlled extension trial. Arthritis Rheum, 44, 202-11.

Agrillo A, Ungari C, Filiaci F, Priore P, lannetti G, 2007. Ozone therapy in the treatment of avascular bisphosphonate-related jaw osteonecrosis. J Craniofac Surg, 18, 1071-5.

Aoyagi T, Morii T, Ohtsuka K, Ohnishi H, Tajima T, Yoshiyama A, Mochizuki K, Satomi K, Ichimura S, 2013. Lung cancer cell line sensitivity to zoledronic acid is bax-dependent. Anticancer Res, 33, 5357-63.

Arce K, Assael LA, Weissman JL, Markiewicz MR, 2009. Imaging findings in bisphosphonate-related osteonecrosis of jaws. J Oral Maxillofac Surg, 67, 7584.

Ariji Y, Izumi M, Gotoh M, Naitoh M, Katoh M, Kuroiwa Y, Obayashi N, Kurita K, Shimozato K, Ariji E, 2008. Mri features of mandibular osteomyelitis: Practical criteria based on an association with conventional radiography features and clinical classification. Oral Surg Oral Med Oral Pathol Oral Radiol Endod, 105, 503-11.

Barragan-Adjemian C, Lausten L, Ang DB, Johnson M, Katz J, Bonewald LF, 2009. Bisphosphonate-related osteonecrosis of the jaw: Model and diagnosis with cone beam computerized tomography. Cells Tissues Organs, 189, 284-8.

Bedogni A, Blandamura S, Lokmic Z, Palumbo C, Ragazzo M, Ferrari $F$, Tregnaghi A, Pietrogrande $F$, Procopio O, Saia G, Ferretti M, Bedogni G, Chiarini L, Ferronato G, Ninfo V, Lo Russo L, Lo Muzio L, Nocini PF, 2008. Bisphosphonate-associated jawbone osteonecrosis: A correlation between imaging techniques and histopathology. Oral Surg Oral Med Oral Pathol Oral Radiol Endod, 105, 358-64. 
Bianchi SD, Scoletta M, Cassione FB, Migliaretti G, Mozzati M, 2007. Computerized tomographic findings in bisphosphonate-associated osteonecrosis of the jaw in patients with cancer. Oral Surg Oral Med Oral Pathol Oral Radiol Endod, 104, 249-58.

Bisdas S, Chambron Pinho N, Smolarz A, Sader R, Vogl TJ, Mack MG, 2008. Biphosphonate-induced osteonecrosis of the jaws: Ct and mri spectrum of findings in 32 patients. Clin Radiol, 63, 71-7.

Chiandussi S, Biasotto M, Dore F, Cavalli F, Cova MA, Di Lenarda R, 2006. Clinical and diagnostic imaging of bisphosphonate-associated osteonecrosis of the jaws. Dentomaxillofac Radiol, $35,236-43$.

Crepin S, Laroche ML, Sarry B, Merle L, 2010. Osteonecrosis of the jaw induced by clodronate, an alkylbiphosphonate: Case report and literature review. Eur J Clin Pharmacol, 66, 547-54.

Cummings SR, Black DM, Thompson DE, Applegate WB, Barrett-Connor E, Musliner TA, Palermo L, Prineas R, Rubin SM, Scott JC, Vogt T, Wallace R, Yates AJ, LaCroix AZ, 1998. Effect of alendronate on risk of fracture in women with low bone density but without vertebral fractures: Results from the fracture intervention trial. JAMA, 280, 2077-82.

Dore F, Filippi L, Biasotto M, Chiandussi S, Cavalli F, Di Lenarda R, 2009. Bone scintigraphy and spect/ct of bisphosphonate-induced osteonecrosis of the jaw. J Nucl Med, 50, 30-5.

Ebetino $\mathrm{FH}$, Hogan AM, Sun S, Tsoumpra MK, Duan X, Triffitt JT, Kwaasi AA, Dunford JE, Barnett $B L$, Oppermann U, Lundy MW, Boyde A, Kashemirov BA, McKenna CE, Russell RG, 2011. The relationship between the chemistry and biological activity of the bisphosphonates. Bone, 49, 20-33.

Freiberger JJ, 2009. Utility of hyperbaric oxygen in treatment of bisphosphonate-related osteonecrosis of the jaws. J Oral Maxillofac Surg, 67, 96-106.

Fullmer JM, Scarfe WC, Kushner GM, Alpert B, Farman AG, 2007. Cone beam computed tomographic findings in refractory chronic suppurative osteomyelitis of the mandible. $\mathrm{Br} \mathrm{J}$ Oral Maxillofac Surg, 45, 364-71.

Garcia-Ferrer L, Bagan JV, Martinez-Sanjuan V, Hernandez-Bazan S, Garcia R, Jimenez-Soriano Y, Hervas V, 2008. Mri of mandibular osteonecrosis secondary to bisphosphonates. AJR Am J Roentgenol, 190, 949-55.
Gomez Font R, Martinez Garcia ML, Olmos Martinez $\mathrm{JM}, 2008$. Osteochemonecrosis of the jaws due to bisphosphonate treatments. Update. Med Oral Patol Oral Cir Bucal, 13, E318-24.

Gutta R, Louis PJ, 2007. Bisphosphonates and osteonecrosis of the jaws: Science and rationale. Oral Surg Oral Med Oral Pathol Oral Radiol Endod, 104, 186-93.

Harris ST, Watts NB, Genant HK, McKeever CD, Hangartner T, Keller M, Chesnut CH, 3rd, Brown J, Eriksen EF, Hoseyni MS, Axelrod DW, Miller PD, 1999. Effects of risedronate treatment on vertebral and nonvertebral fractures in women with postmenopausal osteoporosis: A randomized controlled trial. Vertebral efficacy with risedronate therapy (vert) study group. JAMA, 282, 1344-52.

Kamoun-Goldrat A, Ginisty D, Le Merrer M, 2008. Effects of bisphosphonates on tooth eruption in children with osteogenesis imperfecta. Eur $\mathrm{J}$ Oral Sci, 116, 195-8.

Katz H, 2005. Endodontic implications of bisphosphonate-associated osteonecrosis of the jaws: A report of three cases. J Endod, 31, 831-4.

Khan AA, Sandor GK, Dore E, Morrison AD, Alsahli M, Amin F, Peters E, Hanley DA, Chaudry SR, Dempster DW, Glorieux FH, Neville AJ, Talwar RM, Clokie CM, Al Mardini M, Paul T, Khosla S, Josse RG, Sutherland S, Lam DK, Carmichael RP, Blanas N, Kendler D, Petak S, St-Marie LG, Brown J, Evans AW, Rios L, Compston JE, 2008. Canadian consensus practice guidelines for bisphosphonate associated osteonecrosis of the jaw. J Rheumatol, $35,1391-7$.

Landesberg R, Eisig S, Fennoy I, Siris E, 2009. Alternative indications for bisphosphonate therapy. J Oral Maxillofac Surg, 67, 27-34.

Lee CY, David T, Nishime M, 2007. Use of plateletrich plasma in the management of oral biphosphonate-associated osteonecrosis of the jaw: A report of 2 cases. J Oral Implantol, 33, 371-82.

Lehrer S, Montazem A, Ramanathan L, PessinMinsley M, Pfail J, Stock RG, Kogan R, 2009. Bisphosphonate-induced osteonecrosis of the jaws, bone markers, and a hypothesized candidate gene. J Oral Maxillofac Surg, 67, 159-61.

Leite AF, Figueiredo PT, Melo NS, Acevedo AC, Cavalcanti MG, Paula LM, Paula AP, Guerra EN, 2006. Bisphosphonate-associated osteonecrosis of the jaws. Report of a case and literature review. Oral Surg Oral Med Oral Pathol Oral Radiol Endod, 102, 14-21. 
Marx RE, 2003. Pamidronate (aredia) and zoledronate (zometa) induced avascular necrosis of the jaws: A growing epidemic. J Oral Maxillofac Surg, 61, 1115-7.

Marx RE, Cillo JE, Jr., Ulloa JJ, 2007. Oral bisphosphonate-induced osteonecrosis: Risk factors, prediction of risk using serum ctx testing, prevention, and treatment. J Oral Maxillofac Surg, 65, 2397-410.

Marx RE, Sawatari Y, Fortin M, Broumand V, 2005. Bisphosphonate-induced exposed bone (osteonecrosis/osteopetrosis) of the jaws: Risk factors, recognition, prevention, and treatment. $J$ Oral Maxillofac Surg, 63, 1567-75.

Migliorati CA, Woo SB, Hewson I, Barasch A, Elting LS, Spijkervet FK, Brennan MT, 2010. A systematic review of bisphosphonate osteonecrosis (bon) in cancer. Support Care Cancer, 18, 1099-106.

Naidu A, Dechow PC, Spears R, Wright JM, Kessler HP, Opperman LA, 2008. The effects of bisphosphonates on osteoblasts in vitro. Oral Surg Oral Med Oral Pathol Oral Radiol Endod, 106, 5-13.

Naveau A, Naveau B, 2006. Osteonecrosis of the jaw in patients taking bisphosphonates. Joint Bone Spine, 73, 7-9.

O'Ryan FS, Khoury S, Liao W, Han MM, Hui RL, Baer D, Martin D, Liberty D, Lo JC, 2009. Intravenous bisphosphonate-related osteonecrosis of the jaw: Bone scintigraphy as an early indicator. J Oral Maxillofac Surg, 67, 1363-72.

Pazianas M, Compston J, Huang CL, 2010. Atrial fibrillation and bisphosphonate therapy. J Bone Miner Res, 25, 2-10.

Pazianas M, Miller P, Blumentals WA, Bernal M, Kothawala $P, 2007$. A review of the literature on osteonecrosis of the jaw in patients with osteoporosis treated with oral bisphosphonates: Prevalence, risk factors, and clinical characteristics. Clin Ther, 29, 1548-58.

Phal PM, Myall RW, Assael LA, Weissman JL, 2007. Imaging findings of bisphosphonate-associated osteonecrosis of the jaws. AJNR Am J Neuroradiol, 28, 1139-45.

Raje N, Woo SB, Hande K, Yap JT, Richardson PG, Vallet $\mathrm{S}$, Treister $\mathrm{N}$, Hideshima $\mathrm{T}$, Sheehy $\mathrm{N}$, Chhetri S, Connell B, Xie W, Tai YT, Szot-Barnes A, Tian M, Schlossman RL, Weller E, Munshi NC, Van Den Abbeele AD, Anderson KC, 2008. Clinical, radiographic, and biochemical characterization of multiple myeloma patients with osteonecrosis of the jaw. Clin Cancer Res, 14, 2387-95.
Regezi JA, Sciubba JJ, Jordan RC, Oral pathology: Clinical pathologic correlations, Elsevier Health Sciences, 2012.

Reid IR, 2008. Anti-resorptive therapies for osteoporosis. Semin Cell Dev Biol, 19, 473-8.

Rizzoli R, 2011. Bisphosphonates for postmenopausal osteoporosis: Are they all the same? QJM, 104, 281-300.

Ruggiero SL, Dodson TB, Assael LA, Landesberg R, Marx RE, Mehrotra B, 2009. American association of oral and maxillofacial surgeons position paper on bisphosphonate-related osteonecrosis of the jaws-2009 update. J Oral Maxillofac Surg, 67, 2-12.

Ruggiero SL, Mehrotra B, Rosenberg TJ, Engroff SL, 2004. Osteonecrosis of the jaws associated with the use of bisphosphonates: A review of 63 cases. J Oral Maxillofac Surg, 62, 527-34.

Scarfe WC, Farman AG, Sukovic P, 2006. Clinical applications of cone-beam computed tomography in dental practice. J Can Dent Assoc, 72, 75-80.

Singer SR, Mupparapu M, 2009. Plain film and cbct findings in a case of bisphosphonate-related osteonecrosis of the jaw. Quintessence Int, 40, 1635 .

Soğur E, Önem E, Baksı BG, 2012. Bisfosfanat kullanimina bağli çene kemiğinde gelişen osteonekroz: Etyoloji, risk faktörleri, tani kriterleri ve tedavi alternatifleri. Atatürk Univ Dis, Hek Fak Derg, 22, 83-95.

Sonis ST, Watkins BA, Lyng GD, Lerman MA, Anderson KC, 2009. Bony changes in the jaws of rats treated with zoledronic acid and dexamethasone before dental extractions mimic bisphosphonaterelated osteonecrosis in cancer patients. Oral Oncol, 45, 164-72.

Stockmann P, Hinkmann FM, Lell MM, Fenner M, Vairaktaris E, Neukam FW, Nkenke E, 2010. Panoramic radiograph, computed tomography or magnetic resonance imaging. Which imaging technique should be preferred in bisphosphonateassociated osteonecrosis of the jaw? A prospective clinical study. Clin Oral Investig, 14, 311-7.

Stubinger S, Dissmann JP, Pinho NC, Saldamli B, Seitz O, Sader R, 2009. A preliminary report about treatment of bisphosphonate related osteonecrosis of the jaw with er:Yag laser ablation. Lasers Surg Med, 41, 26-30.

Suresh E, Pazianas M, Abrahamsen B, 2014. Safety issues with bisphosphonate therapy for osteoporosis. Rheumatology (Oxford), 53, 19-31. 
Unger E, Moldofsky P, Gatenby R, Hartz W, Broder $\mathrm{G}, 1988$. Diagnosis of osteomyelitis by $\mathrm{mr}$ imaging. AJR Am J Roentgenol, 150, 605-10.

Vassiliou V, Tselis N, Kardamakis D, 2010. Osteonecrosis of the jaws: Clinicopathologic and radiologic characteristics, preventive and therapeutic strategies. Strahlenther Onkol, 186, 367-73.

Verron E, Bouler JM, 2014. Is bisphosphonate therapy compromised by the emergence of adverse bone disorders? Drug Discov Today, 19, 312-9.

Walter C, Al-Nawas B, du Bois A, Buch L, Harter P, Grotz KA, 2009. Incidence of bisphosphonateassociated osteonecrosis of the jaws in breast cancer patients. Cancer, 115, 1631-7.

Walter C, Al-Nawas B, Grotz KA, Thomas C, Thuroff JW, Zinser V, Gamm H, Beck J, Wagner W, 2008. Prevalence and risk factors of bisphosphonateassociated osteonecrosis of the jaw in prostate cancer patients with advanced disease treated with zoledronate. Eur Urol, 54, 1066-72.

Woo SB, Hellstein JW, Kalmar JR, 2006. Narrative [corrected] review: Bisphosphonates and osteonecrosis of the jaws. Ann Intern Med, 144, 753-61.

Yazışma Adresi:

Yrd. Doç. Dr. Elif TARIM ERTAŞ

İzmir Katip Çelebi Üniversitesi

Diş Hekimliği Fakültesi

Ağız Diş ve Çene Radyolojisi AD

iZMiR

Tel: +90 (232) $3254040-2352$

E-mail: dteliftarim@yahoo.com 